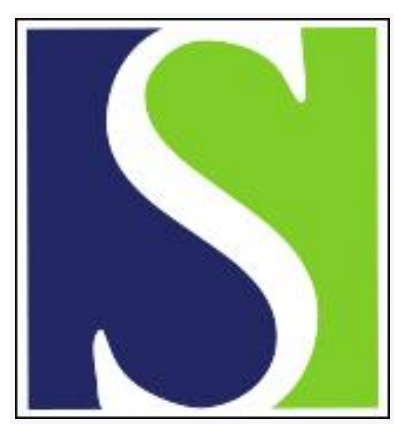

Scand J Work Environ Health 1982;8(2):85-93

https://doi.org/10.5271/sjweh.2484

Issue date: Jun 1982

\title{
Long-term development of occupational accidents in Finland.
}

by Saari J

Key terms: accident rate; accident statistics; Finland; long-term development; occupational accident; review; safety measure

This article in PubMed: www.ncbi.nlm.nih.gov/pubmed/7134931

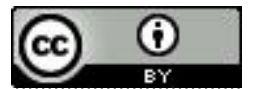




\title{
Long-term development of occupational accidents in Finland
}

\author{
by Jorma Saari, DTech ${ }^{1}$
}

\begin{abstract}
SAARI J. Long-term development of occupational accidents in Finland. Scand $j$ work environ health 8 (1982) 85-93. In Finland the number of occupational accidents has been increasing throughout the $1900 \mathrm{~s}$. This increasing long-term development is related to the improved insurance coverage of workers. The severity of accidents has decreased during the past three decades. Accident curves show variations related to fluctuations in the national economy. The occurrence of accidents seems to be very sensitive to economic determinants. The structural changes of work brought about by automation should lead to a decrease in the occurrence of accidents. With the exception of economic factors and structural changes in the labor force, no signs of any major decrease in the occurrence of accidents have been detected.
\end{abstract}

Key terms: accident rates, accident statistics, safety measures.

Because injury is an event which is easy to record, accident statistics are compiled in all developed countries. Occupational accidents are often used as a measure of the effectiveness of occupational health and safety activities. However, the use of accidents as a measure of the safety of workplaces can be questioned in that it measures safety indirectly as unsafety (7, 9).

A number of factors determine what events are called accidents. First of all, an occupational accident is a concept defined by law. For this reason, legal changes and legislative differences between countries influence the number of events recorded as accidents $(4,5)$.

An accident is an indication of the malfunctioning of a sociotechnical system. Therefore, in addition to the technical factors (technical safety), social factors which determine human behavior also influence the recording of accidents.

The unemployment rate, workers', physicians' and managements' behavioral norms of the social acceptability of ac-

1 Tampere University of Technology, Tampere, Finland.

Reprint requests to: Prof $\mathrm{J}$ Saari, Tampere University of Technology, PO Box 527, SF-33101 Tampere 10, Finland. cidents $(3,10)$, and the accessibility and acceptability of health services (6) are some factors which influence the decision of whether or not an event is reported and recorded as an accident.

The objectives of this article are (i) to describe the long-term development of occupational accidents in Finland, (ii) to estimate the degree to which the inclination towards accidents can be calculated for a nationwide sociotechnical system, and (iii) to analyze the influence of economic factors on accident trends.

\section{Definition of an accident}

In Finland, current laws and statistical practice define an occupational accident as follows: (i) an event which leads to physical injury (maximum time interval between the event and the resultant injury, $24 \mathrm{~h}$ ), (ii) one that leads to an absence from. work of more than $3 \mathrm{~d}$, (iii) one in which the injured person is an employed worker who is thus covered by accident insurance, and (iv) one that occurred at work or under work-related circumstances.

The definition has been modified by some changes in legislation and statistical procedures. The major changes are listed 
in table 1. The amendment of the Accident Insurance Act in 1972 is the only change which may have increased (more than $1-2 \%$ ) the total number of accidents notably.

\section{Frequency, severity and types of accidents}

The development of the total number of registered occupational accidents in Fin- land is shown in fig 1 . The same figure also indicates the number of employees (the total work population is now around 2.2 million). The overall development in both curves is very similar. The first phase of industrialization in Finland began during 1920-1930; this development is clearly reflected both by the accident figures and also by the number of insured workers.

Both curves in fig 1 also show the depression of the early 1930s. At the same

Table 1. Modifications in injury compensation and in statistical procedures during the past 30 a.

\begin{tabular}{|c|c|c|c|}
\hline Year & Law & Statistical procedures & $\begin{array}{c}\text { Equality between number } \\
\text { of hours worked and the } \\
\text { annual worker }\end{array}$ \\
\hline 1948 & $\begin{array}{l}\text { Accident Insurance Act } \\
\text { (20 August 1948); Occu- } \\
\text { pational Diseases Act } \\
\text { amended (30. December } \\
\text { 1948) }\end{array}$ & & $\begin{array}{l}\text { One annual worker }= \\
2,400 \mathrm{~h} \text { worked }\end{array}$ \\
\hline 1959 & $\begin{array}{l}\text { Accident Insurance Act } \\
\text { amended (7 November } \\
\text { 1958); compensations rais- } \\
\text { ed }\end{array}$ & & \\
\hline 1960 & & $\begin{array}{l}\text { Classification of industry re- } \\
\text { vised to conform to interna- } \\
\text { tional standard }\end{array}$ & \\
\hline 1964 & & $\begin{array}{l}\text { Statistics compiled by com- } \\
\text { puter for first time - Acci- } \\
\text { dents at work and traveling } \\
\text { to or from work separated }\end{array}$ & \\
\hline 1967 & $\begin{array}{l}\text { Occupational Diseases Act } \\
\text { renewed }(29 \text { December } \\
1967)\end{array}$ & $\begin{array}{l}\text { Total number of fatal cases, } \\
\text { even those not finally decid- } \\
\text { ed, estimated and included }\end{array}$ & \\
\hline 1968 & & $\begin{array}{l}\text { Classifications revised (bran- } \\
\text { ches of industry, types of ac- } \\
\text { cidents) } \\
\text { Included only those cases } \\
\text { finally decided (prior to } 1968 \text {, } \\
\text { the number of cases not fi- } \\
\text { nally decided } 3 \text { a after the } \\
\text { occurrence of an accident } \\
\text { estimated and included) }\end{array}$ & \\
\hline 1970 & & & $\begin{array}{l}\text { One annual worker }= \\
1,920 \mathrm{~h} \text { worked }\end{array}$ \\
\hline 1972 & $\begin{array}{l}\text { Accident Insurance Act } \\
\text { amended ( } 17 \text { March 1972), } \\
\text { pain in muscles or ten- } \\
\text { dons due to work move- } \\
\text { ments compensable }\end{array}$ & & \\
\hline $1973-1975$ & & Statistics not compiled & \\
\hline 1976 & & Classifications revised & \\
\hline 1978 & & & $\begin{array}{l}\text { One annual worker }= \\
1,750 \mathrm{~h} \text { worked }\end{array}$ \\
\hline
\end{tabular}


time, technology developed; main shaft drives were replaced by individual electric motors, which were much easier to guard. This technological improvement in machine safety is reflected in the slow increase of occupational accidents between 1930 and 1950, although other factors must have interferred in the process during World War II. Another rapid increase in the number of employees - and, partly, in accidents as well - began immediately after the war and has continued to recent years.

In fig 1 a certain fluctuation in the total number of accidents is evident for the postwar period $(2,3)$. The general trend is an increasing one; it corresponds quite well with the increase in the number of employees. However, the economic situation of the country has undergone a recessive cycle every 10 a. The Finnish currency was devaluated in 1958, in 1967, and in 1977-1978. The number of accidents always declined before these years, and afterward the occurrence of accidents began once again to increase. This increase in the number of accidents after recession seems to be recurring again now.

The total number of fatal accidents is shown in fig 2 . The increase in the number of fatal accidents halted after 1930 due to the technological measures of improved machine guarding. After the war (since 1945), the trend has been decreasing, a development which is contradictory to the total number of all reported occupational accidents.

Similar patterns can be found for accident frequency rates. The number of accidents per thousand annual workers is shown in fig 3 . The frequency rates were at their lowest levels during periods of economic depression.

The frequency rate for accidents in 1973-1975 can partly be deduced from the data of fig 4, which shows the number of occupational accidents reported to insurance companies per million manhours covered by insurance. In addition to those accidents recorded in the official statistics, the accidents reported to the insurance companies also include (i) accidents on the way to or from work and (ii) minor accidents which lead to compensation but not necessarily to absence from work. Thus, for example, changes in insurance forms may influence the number of accidents reported. However, these figures are reliable enough to allow conclusions about the most probable development according to the criteria used in the official statistics.

The frequency rate of fatal accidents,

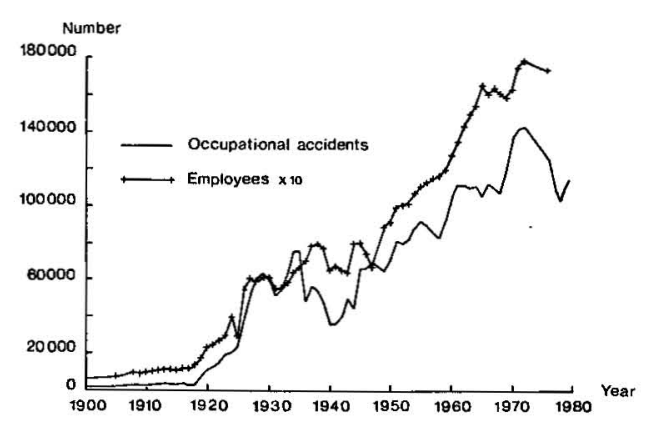

Fig 1. Number of occupational accidents and embloyees according to official statistics $(1,11)$.

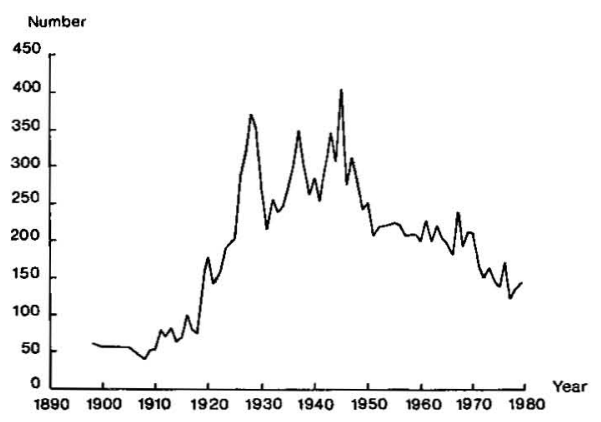

Fig 2. Fatal occupational accidents $(1,11)$.

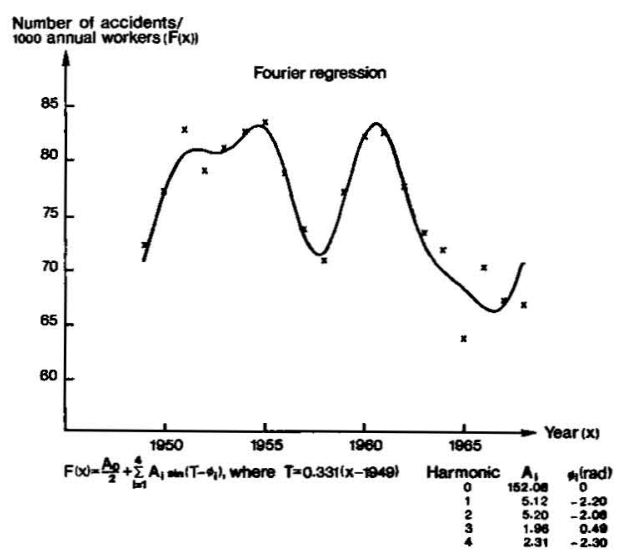

Fig 3. Number of occupational accidents $/ 1,000$ annual workers (1949-1968). The curve which connects the points was plotted by the Fourier regression curve equation, with four harmonics. 
calculated as the number of fatal accidents per thousand annual workers, shows a steadily diminishing trend for the past 25 a (fig 5). The best fit of a regression curve is achieved by an exponential curve

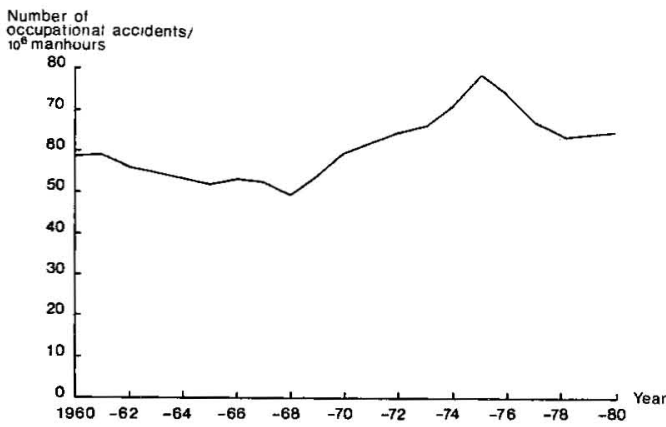

Fig 4. Number of occupational accidents $/ 10^{6}$ manhours reported to the insurance companies. All accidents which led to compensation are included (even accidents on the way to or from work).

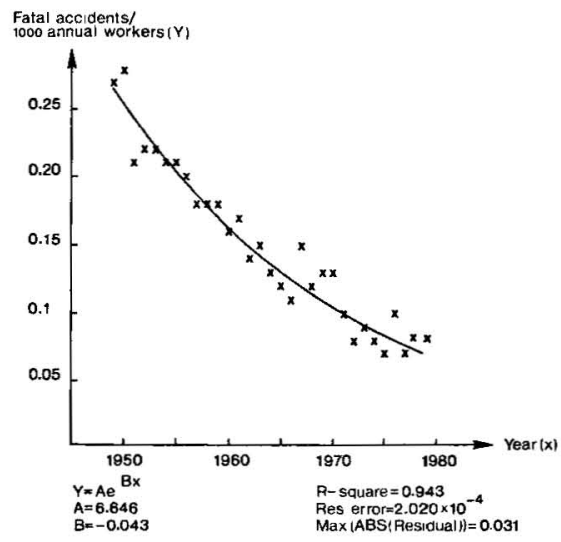

Fig 5. Fatal accidents $/ 1,000$ annual workers for the period 1949-1979 (11).

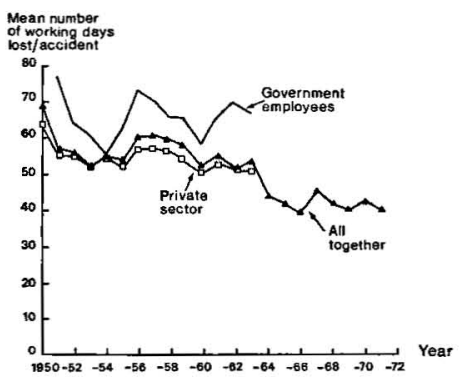

Fig 6. The average number of workdays lost per accident. Accidents to or from work are included until 1964 (11). which indicates that the rate of decrease is diminishing. A linear regression gives a slightly worse fit. If the decrease were linear, the zero level would be reached by 1987. For reasons not yet discussed, this occurrence does not seem possible.

The mean number of workdays lost per accident decreased between 1950 and 1972 (fig 6). Unfortunately, later figures are not available from the official statistics. No obvious regularities related to the economic situation can be found in this curve. Fatal accidents caused about $27-34 \%$ of those workdays lost between 1950 and 1970. (For each fatality, 6,000 lost days were used for the calculations). The same figure for accidents leading to temporary disability varied between 32 and $39 \%$.

The percentage of accidents causing a loss of less than seven workdays increased slightly from 1950 to 1970 . In $194917 \%$ of all accidents led to less than $7 \mathrm{~d}$ of absence; the figure was $21 \%$ in 1950 and $25 \%$ in 1951 . This trend most likely reflects an increasing awareness of the then new act on accident compensation. After 1951 there were no sudden changes in this percentage, although by 1967 it had gradually climbed to 29 . These data support the view that variations in the total number of accidents are not due to a sudden change in the accident concept; in other words, minor accidents do not explain the variations in the total number of accidents.

Fig 7 and 8 present the types of accidents. Unfortunately, the classifications have been modified several times in the past 15 a. Between 1950 and 1963 the distribution of the types of accidents was fairly stable. The fluctuation in the total number of accidents is not reflected in these curves. These figures show that accidents involving slipping or falling have steadily become more frequent, while accidents occurring during the use of hand tools have become less frequent. Accidents related to machines and the handling of objects remained roughly constant until 1964. The change from 1963 to 1964 must at least partly be due to a change in statistical procedures. The figures for the preceding years were calculated on the basis of all occupational accidents, but, from 1964 on, they have been calculated only on the basis of accidents that occurred at work. It is possible that a real change 
due to advances in automation occurred simultaneously.

From 1868 on, the statistics are more difficult to handle. The percentage of accidents due to high or low temperatures has been constant for the entire period despite fluctuation in the total number of accidents. Because of changes in classifications, other accident categories from 1968 to 1973 and from 1976 to 1978 cannot be so directly compared.

Overexertions have become more prevalent, but it is hard to evaluate to what extent the increase is determined by a real change in reporting and to what extent by statistical changes.

The distribution of accidents was surprisingly stable from 1976 to 1978 , even though the total number of accidents decreased from 125,000 in 1976 to 102,500 in 1978.

\section{Regression analysis}

Various regression techniques were used to determine whether any regular cyclic variations could be detected for the total number of accidents recorded in the official statistics between 1950 and 1978 . (Estimated figures had to be used for 1973-1975). Polynomial regressions did not lead to a stable formula that could be used for the prediction of future figures. The fit with the data was good with fifth and sixth degree polynomials, but estimates for the forthcoming years show completely unstable and impossible figures. The second degree polynomial yielded stable estimates but could not take into consideration the cyclic variations (fig 9). According to this equation, a flattening phase in the curve has been reached. However, the curve is still only a rough estimate of the real process, and therefore its value for prediction is questionable.

The points of the accident frequency rate (fig 3) were satisfactorily connected by a Fourier regression curve, even with less than ten harmonics. The calculations were based on figures for 1949-1968. A formula with four harmonics fairly accurately predicts the development up to 1976. For 1969-1972, the error is less than two accidents 1,000 annual workers. The error is four accidents for 1976 and 20 for 1978. The formula proposes the lowest

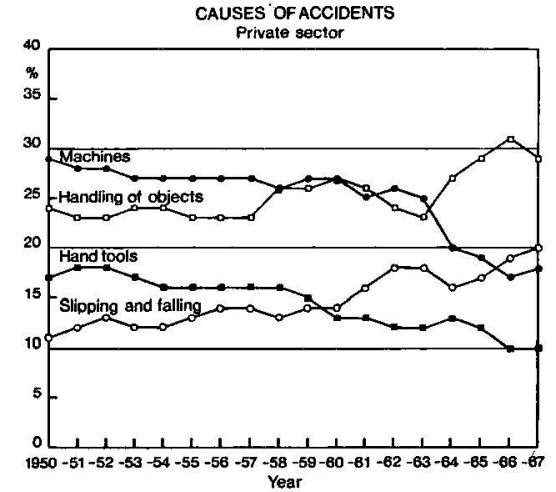

Fig 7. "Causes" of accidents. The figures for 1950-1963 are based on all occupational accidents; those for 1964-1967 are based only on accidents which occurred at work (11).

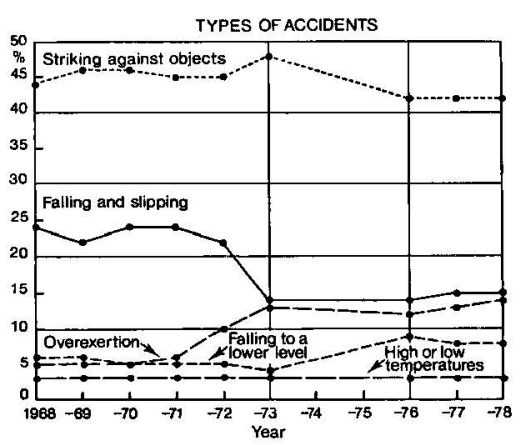

Fig 8. Types of occupational accidents. In 1973 those accidents which led to less than three lost days were included. No data exist for 1974 1975 (11).

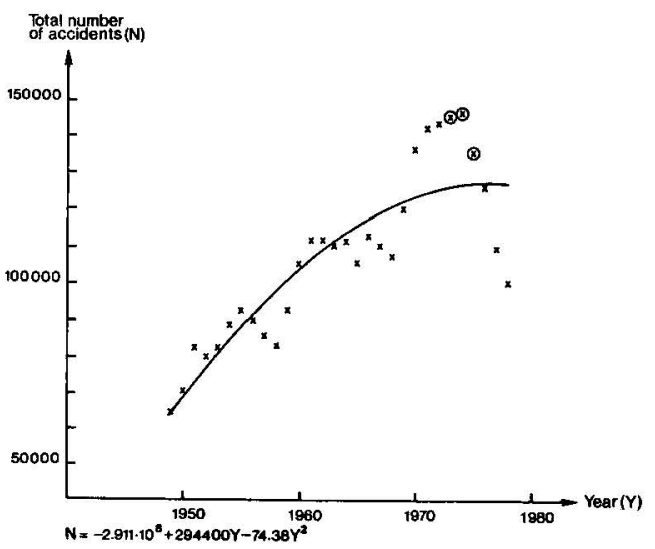

Fig 9. Second-degree polynomial fitted to the total number of accidents for the period 19491978, data for 1973, 1974 and 1975 estimated from statistics published by insurance companies. 


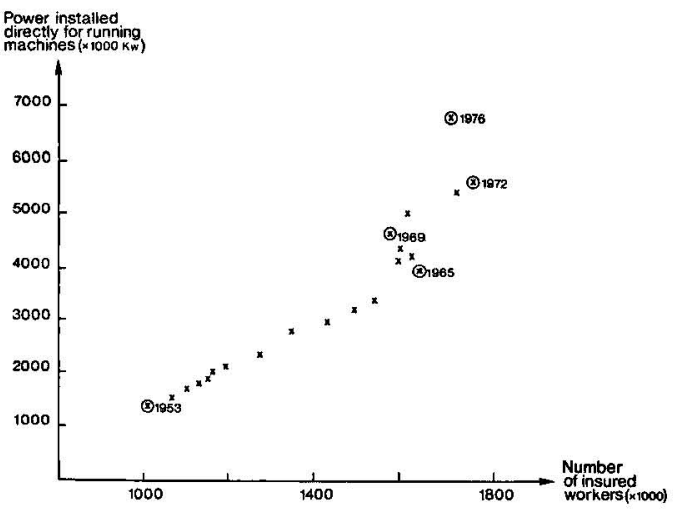

Fig 10. Relationship between the number of employees and power installed for the operation of machines $(1,11)$.

Table 2. Some of the organizational measures taken during the past 10 a to improve occupational health and safety conditions in Finland.

Year Action

1969 Agreement between parties of the labormarket with regard to occupational safety at workplaces. - Result: Center of Occupational Safety and branch committees for occupational health and safety work established

1973 Acts passed concerning occupational health and safety control at workplaces Result:

a. National Board of Labor Protection established and the factory inspectorate revised

b. Became necessary to establish a safety committee in companies with more than 20 employees and select a safety representative of the workers in companies with more than 10 employees

1974 Labor Protection Laboratory established in the State Technical Research Center

1974 Professorship in safety engineering established at the Tampere University of Technology and improved possibilities to teach in this field arranged at other universities

1978 Acts passed concerning the Institute of Occupational Health, with no immediate consequence - the Institute had previously been strengthened, reorganized and its resources improved (1973 on)

1970-Many other new activities started and 1980 activities rearranged within various organizations figures for 1977; in reality, the minimum was reached in 1978.

The shape of the frequency rate curve is, after all, not that regular for three $10-\mathrm{a}$ periods: $1949-1958,1959-1968$ and $1969-$ 1978. Thus it is difficult to construct a meaningful, simple mathematical model for the cyclic variations. The mechanisms behind the variations might be different or at least of different magnitude. One possible reason is the gradual change of weekly workhours from 45 to 40 , a change which occurred between 1964 and 1968 .

It was assumed that the number of accidents and the accident frequency rate are related to the economic situation of the country. The stock exchange index was assumed to give an overall reflection of the economic situation.

The correlation coefficient of the number of accidents and the index raised to the power of 0.335 was 0.92 for 1950-1972. When the change, from the preceding year, in these two variables was calculated, 16 out of 23 pairs yielded the same sign. The pairs of different signs occurred in years when, according to the index, the economic situation was in the process of changing directions (with one exception).

Because of large variations in the index, the correlation coefficient would be lower if the last decade were included. Still, the sign of change of either variable would be the same.

In order that variables which reflect the economic activity of the country could be taken into account in the explanation of the absolute numbers of accidents or their frequency rates, a number of other analyses were carried out. The variables used were the number of insured workers, the percentage of unemployment, the index of industrial production, the index of real domestic production, power installed directly for the operation of machines, and the traffic of commercial goods on the Finnish railroads. None of these variables yielded a good model. The difficulties were partly mathematical and partly due to the questionable quality of the statistical time series. A proper predictive model cannot be constructed on the basis of these indirect independent variables, which reflect national economic activities.

One interesting correlation was noticed however. Power installed directly for the 
operation of machines and the number of insured workers shows an amazingly linear relationship between 1953 and 1965 (fig 10). This phenomenon indicates that workers had to be employed for each new machine.

After 1965 the number of new workers has not increased congruently with the installation of new machines. Therefore mechanization must have changed in character after 1965 . It has become automation which influences the conditions and the prevention of accidents. Some of the accidents which occur must involve the new mechanisms; the accidents must occur in tasks like maintenance and repair, when machine guarding is not easily possible.

\section{Measures taken to improve safety}

From the national point of view the most interesting period with respect to safety is 1970 - 1979, because many new acts were implemented and new activities initiated. In Finland so many measures were never before taken in so short a period of time to improve occupational health and safety conditions. Table 2 lists some of the measures taken. Unfortunately the effects can be estimated only indirectly because (i) sufficient statistics are not available for 1973-1975, (ii) the statistics for other years are too incomplete for a full comparison, and (iii) many economic, technological and social factors have radically changed during the past few years.

The total number of occupational accidents, as well as the frequency rate, decreased from 1975 to 1978 . The total number of accidents in $\mathbf{1 9 7 8}$ even reached the level of 1960 . However, the total number of occupational accidents is again increasing at the same rate as after earlier periods of depression.

It must be remembered that the economic situation in Finland has recently been exceptionally poor. The unemployment rate has been higher than ever recorded. Young people have been especially hard hit by unemployment (fig 11). 'Young men (age group 15-24 a) have an accident frequency rate which is around 140-170 accidents per $10^{6}$ manhours. It is twice the accident frequency rate of men over 30 . Due to unemployment, approximately $20-25,000$ occupational accidents did not occur in 1978. For 1972 the same figure was about 6,000 . This calculation takes into account only those hours which were not worked. The abnormal economic situation also produces other factors which diminish the number of accidents, eg, a lower rate of turnover, less hasty production, and improved production planning.

A number of structural changes took place during the past decade. More and more people work in offices and at other jobs in which certain accident conditions are not found. Fig 12 shows the number of blue-collar and white-collar workers in Finland. The number of blue-collar workers has remained at the same level, except for the last few years. The number of white-collar workers has increased steadily.

It is worth noting that also accidents occurring on the way to or from work have decreased in number. Fatal accidents of this category have decreased in proportion to fatal accidents at work. Less severe accidents are not accurately registered in the official statistics. Based on a sample, the number of accidents occurring on the way to or from work decreased from 25,000 in 1976 to 20,000 in 1977 (about 18,000 in

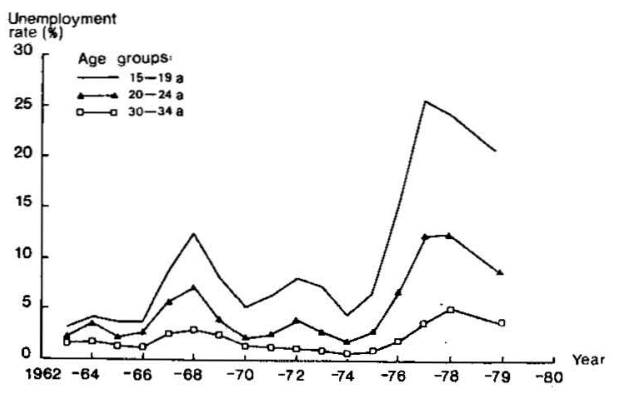

Fig 11. Rate of unemployment $(\%)$ for those between 15 and 34 a of age (1).

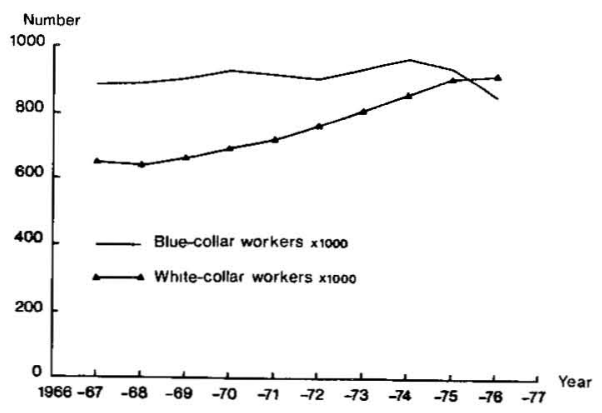

Fig 12. Number of blue- and white-collar workers during the past decade (1). 
both 1978 and 1979). The decrease was $20 \%$, while the decrease in accidents at work was $13 \%$. This result must partly be due to unemployment, but it may also be partially due to a lower work load.

\section{Discussion}

The number of registered occupational accidents in Finland has increased during this century. The first improvement in the accident curve occurred around 1930. The basic principles of machine guarding and accident prevention in general, as well as technology, were developed and implemented during that time. The rapid increase in accidents was slowed down in this way for the next two or three decades.

This knowledge seemed to lead to a steady state in which variations were introduced primarily by changes in the economic activity of the country. This kind of close relationship to the economy has also been observed in the Federal Republic of Germany $(2,8)$.

The second juncture most probably occurred around 1965-1968 even though it cannot be seen in the accident figures for those years. The implementation of automation on a larger scale began then. Direct production jobs began to diminish because machines were able to control themselves to a certain degree. Administrative jobs, services, etc, were needed more and more. This development has had the following two consequences with respect to accidents: (i) the number of people directly exposed to the risk of accidents began to decrease and (ii) accident risks attained a new character which makes the old principles of accident prevention less applicable, eg, repair tasks in which machine guarding cannot be utilized.

For the past 30 a the curve indicating the number of occupational accidents in Finland has shown a pattern visibly similar to a 10-a cycle. This visible regularity could not be constructed into a mathematical model. The conclusion is that, underneath this process, different determinants varying in strength influence the development of the accident curve.

The overall trend of accident occurrence has been increasing for the past $30 \mathrm{a}$. The last decade shows a deviation from this trend.
The number of accidents first increased rapidly and then decreased as fast. The abrupt accident increase gives the impression of being too high. The causes might be the expansion of health services at workplaces, a social atmosphere favorable for reporting minor accidents, and the compensation of some new types of injuries. At the end of the last decade, the number of accidents may possibly have been at a normal level.

Accidents have become less severe, a positive development which might partly be a reflection of the improved quality and quantity of health services. Injuries which formerly led to death are no longer fatal.

On the whole, the accident analysis supports the following conclusions: (i) the severity of accidents has decreased (Fatal accidents in particular have become more infrequent.); (ii) the decline in the number of accidents for the past few years may be an illusory improvement caused by economic conditions instead of one representing a higher degree of safety; (iii) a decrease in the total number of accidents and a decrease in the frequency rate are to be expected as the result of automation and the increasing number of white-collar workers; and (iv) because of automation and mechanization, the traditional principles of accident prevention may now be invalid - at the very least, they need to be reassessed.

Because of the sensitivity of accidents to economic factors, the estimation of the effects of safety measures on the national level is restricted. The absolute numbers, as well as the accident frequency rates, fluctuate according to changes in the economic situation. The factors behind these fluctuations are the unemployment of young people, reduced turnover, lower production rates in general, and improved production planning, together with ample time for production.

\section{References}

1. Central Statistical Office of Finland. Statistical yearbook of Finland 1910-1978. Helsinki 1911-1979.

2. Compes PC. Betriebliche Fehlzeiten durch Unfälle. Arbeitswissenschaft (1966) 101105.

3. Harper DG, Lister EG, Middleton M. A study of regional variation in workdays 
lost through accidents. Accid anal prev 3 (1971) 229-236.

4. McFarland RA. Critique of accident research. Ann ny acad sci 107 (1963) 686-695.

5. McFarland RA. Injury - A major environmental problem. Arch environ health 19 (1969) 244-256.

6. Powell P, Hale M, Martin J, Simon M. 2000 accidents. National Institute of Industrial Psychology, London 1971.

7. Rockwell TH, Bhise VD, Clevinger TR. Development and application of a nonaccident measure of flying safety performance. J saf res 2 (1970) 240-250.

8. Skiba R. Taschenbuch Arbeitssicherheit.
Erich Schmidt Verlag, Bielefeld 1979.

9. Smillie RJ, Ayoub MA. A computer simulation approach for analyzing occupational accidents. $J$ occup accid 1 (1976) 47-68.

10. Verhaegen $P$, Vanhalst $B$, Dericjke $H$, van Hoecke M. The value of some psychological theories on industrial accidents. $J$ occup accid 1 (1976) $39-45$.

11. Industrial accidents. In: Official statistics of Finland. 26 (1955-1979) 15-30.

Received for publication: 29 September 1980 